\title{
Wind tunnel flux comparisons using a phase Doppler interferometer
}

\author{
Roy L. Roten ${ }^{1 *}$, Scott L. Post ${ }^{1}$, Armin Werner ${ }^{1}$, Majeed Safa ${ }^{2}$, Andrew J. Hewitt ${ }^{3}$ \\ ${ }^{1}$ Department of Precision Application, Lincoln Agritech Ltd., P.O. Box 69133, Lincoln, Christchurch 7640, New Zealand \\ ${ }^{2}$ Department of Commerce, Lincoln University, P.O. Box 7647, Lincoln, Christchurch 7647, New Zealand \\ ${ }^{3}$ School of Agriculture and Food Science, The University of Queensland, Gatton QLD 4343, Australia
}

\section{Vol. 57, No. 3: 281-287, 2017 \\ DOI: 10.1515/jppr-2017-0040}

Received: June 19, 2017

Accepted: September 12, 2017

${ }^{*}$ Corresponding address: rory.roten@lincolnagritech.co.nz

\begin{abstract}
It is essential to know the movement of droplets in time and space (i.e. flux) when measuring and/or predicting spray drift in agricultural application. A study was performed to assess the flux measurements of a phase Doppler system against a standard monofilament system in a wind tunnel. The primary objectives of the study were to compare flux from a new phase Doppler system against $1.7 \mathrm{~mm}$ cotton and $2.0 \mathrm{~mm}$ nylon strings at varying wind speeds $\left(1.4,4.2,8.3,12.5\right.$, and $\left.16.7 \mathrm{~m} \cdot \mathrm{s}^{-1}\right)$ and spray exposures times $(5,10,15,30$, and $60 \mathrm{~s})$ with an overarching hypothesis that the active, phase Doppler is able to accurately measure the flux regardless of exposure and spray mass whereas the static string samplers are limited to a maximum retention. The phase Doppler did measure linearly as expected, however strings did not reach a point in which they loss mass; conversely, they appeared to overload with saturation. These findings are believed to be among many variables which influence the variability of previous mass balance studies.
\end{abstract}

Key words: flux monofilament system, phase Doppler system, wind tunnel

\section{Introduction}

As pesticides are applied, the sprayed liquid solution is typically forced through the small orifice of a nozzle which begins the process of atomization, resulting in the formation of an aerosol spray. Spray characteristics change depending on the physical characteristics of the given nozzles (e.g. presence or absence of a venturi, designs, size and shape of exit and any pre-orifices), the characteristics of the sprayed (especially the viscosity and surface tension), and the spray pressure. Once released through a nozzle, a spray will be affected by meteorological conditions such as relative humidity, temperature, wind speed and wind direction, the external forces such as the operator's driving speed and physical field conditions (e.g. the terrain angle and roughness). Finally, the selected operating pressure will dictate how much force is applied to the spray as it passes through the nozzle, which is the first point of contact that will influence atomization and the production of fine droplets: the higher the pressure and the smaller the orifice, the finer the overall droplet spectrum will be for hydraulic nozzles (Nuyttens et al. 2007).

To assess how particular nozzles will influence a spray under different pressures and liquid physical properties, wind tunnels or spray chambers are typically used. The wind tunnel provides a relatively controlled environment, whereas in-field assessment presents dynamic conditions of meteorology, hardware/sprayer configuration, surface terrain, and driving speed. In wind tunnels, laser based technologies such as laser diffraction (e.g. those manufactured by Malvern and Sympatec), imaging and forward scattering probes (e.g. Particle Measurement System - PMS), and phase Doppler systems (e.g. Artium, Dantec and TSI PDA/ PDPA/PDI instruments) have predominantly been 
used to measure the key spray characteristics of droplet size, velocity and flux. The validity of phase Doppler compared to other drop sizing systems was shown by Hoffmann et al. (2013). However, the choice of spray measurement system affects the type of data acquired. For example, only phase Doppler and pulsed imaging technologies are able to instantaneously measure velocity and flux. Laser diffraction devices typically only provide droplet size distributions, while PMS and other imaging technologies have been successfully tested to measure flux and velocity but require further calculations of flux (Goguen et al. 1997). Further, flux in a wind tunnel can be assessed using various collection systems such as monofilament line and strings to act as static collectors; the cumulative loading of these strings with a tracer sprayed at a known concentration can be converted into a flux measurement which is common (Fritz et al. 2011). However, as with many physical and intrusive samplers, considerable handling is required to harvest and store the sampler and extract the tracer which was accumulated.

In theory, a phase Doppler system should be able to provide reliable, in-situ flux measurements and eliminate some of the handling and human error issues associated with intrusive and passive sampling. The phase Doppler system presented here is the Demeter PDI (Artium Technologies, Inc, Sunnyvale, California, USA), which was recently discussed in detail (Roten et al. 2016) as part of series of studies using the Demeter PDI for in-field droplet assessment and mass quantification. In short, this particular PDI is different than most other laser measuring devices used in agricultural spray assessment in that it is an enclosed, portable unit which allows the PDI to be used out of laboratory environments and potentially used in the diverse environments in which pesticides are applied. Early attempts at using PDA technology to measure spray volume flux failed as the probe size was in fact dependent on the drop size. Artium's PDI is able to overcome this difficulty by correcting the probe volume for each drop size class, following the procedure of Bachalo et al. (1988). The primary objective of this study was to compare flux data from two string materials to the flux data obtained from the Demeter PDI using exposure time and wind speed as treatments. It was hypothesized that the flux data from all three collectors will agree until a certain time and/or threshold wind speed when string collectors will begin to lose collected material through runoff following saturation and/or shattering; the PDI, as an active non-intrusive collector will reliably collect data regardless of exposure time or aerosol load. Secondary objectives were to assess the differences between adsorption and absorption of the two string types with the hypothesis that fibrous string material will collect more spray mass when high cumulative loading is expected due to the fibrous string's ability to absorb whereas the dense, non-permeable, smooth nylon string can only adsorb until it becomes saturated and loses mass due to droplets falling off.

\section{Materials and Methods}

\section{Wind tunnel arrangement}

This experiment was conducted at the University of Queensland Wind Tunnel Facility (Gatton, Australia). A $1 \times 1 \mathrm{~m}$ working section was selected to achieve wind speeds between 1 and $60 \mathrm{~km} \cdot \mathrm{h}^{-1}$. Wind tunnel set up (Fig. 1) consisted of the spray nozzle oriented in a downward fashion with the spray tip offset $45^{\circ}$ and $80 \mathrm{~cm}$ from the wind tunnel floor; nozzle orientation was selected to make the most use of the spray cloud by keeping the spray within the airflow and not on the wind tunnel walls. Cotton $(1.7 \mathrm{~mm}$ piping cord, Birch Haberdashery, Heidelberg, Victoria, Australia) and nylon (2 mm, Stihl, Weingärten, Germany) strings were alternatively mounted at 39 or $41 \mathrm{~cm}$ high, $1 \mathrm{~m}$ downwind of the nozzle. The PDI was positioned directly behind the strings at a sampling height of $40 \mathrm{~cm}$ which, due to the probe design, placed the sampling volume $10 \mathrm{~cm}$ behind the strings. Because time constraints and environmental conditions are constantly in conflict, all samplers per run were tested simultaneously. To generate the spray, a XR80-015 nozzle (Teejet Spraying Systems, Wheaton, Illinois, USA) was operated at $350 \mathrm{kPa}$ for a flow rate of $600 \mathrm{ml} \cdot \mathrm{min}^{-1}$; this nozzle was selected to provide a finely sized spray for maximum sampling frequency for the phase Doppler.

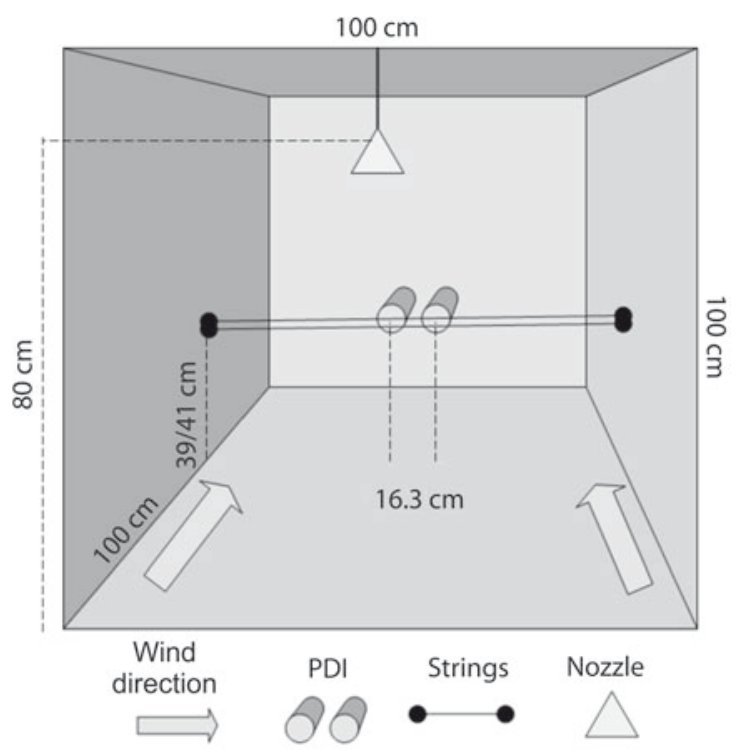

Fig. 1. Schematic of tunnel set up 


\section{Sampling procedure}

The treatment matrix included wind speeds of approximately: $1.4,4.2,8.3,12.5$, and $16.7 \mathrm{~m} \cdot \mathrm{s}^{-1}$ $\left(5,15,30,45\right.$, and $60 \mathrm{~km} \cdot \mathrm{h}^{-1}$, respectively) and spray exposure times of $5,10,15,30$, and $60 \mathrm{~s}$. Wind speeds were assessed at the point of sampling using a hand held anemometer (Kestrel 4500, KestrelMeters, 2241 Cole Street, Birmingham, MI, USA). Precise wind speeds were not relevant as all treatments occurred simultaneously.

In order to measure spray flux with passive string collectors, a spray solution which contained water and $1 \% \mathrm{v} / \mathrm{v}$ Pyranine 10G fluorescent dye (Keystone Aniline Corporation, Kansas USA) was added. After the given treatment was complete, samples were immediately harvested which consisted of the middle $16.3 \mathrm{~cm}$ (the distance between the two PDI uprights) and placed into individual re-sealable bags which were stored in the dark in a freezer until processing. The phase Doppler voltage was set at $250 \mathrm{~V}$ for all measurements which was validated beforehand to provide the most reliable data based upon the density and volume of the spray.

All samplers were replicated six times in total: three consecutive replications per day for two days. Consecutive replications were essential in the repeatability of the study to support uniformity in all other variables, especially the wind speed in the wind tunnel working section.

\section{Flux, collection efficiency and droplet assessment}

PDI volume flux $\left(V^{\prime \prime}\right)$ is calculated with Artium's AIMS software using Equation 1 (Anonymous 2013). To convert the PDI's volume flux data to a comparable unit to string deposition, the $V^{\prime \prime}$ was multiplied by the total time $\left(t_{\text {tot }}\right)$ (Eq. 2) to obtain volume deposition per unit area, $V_{\text {dep }}$.

$$
\begin{gathered}
V^{\prime \prime}=\frac{V_{\text {tot }}}{t_{\text {tot }} A_{\mathrm{p}}}=\left(\frac{\pi}{6}\right) \frac{N_{\text {tot }} D_{30}^{3}}{t_{\text {tot }} A_{\mathrm{p}}}, \\
V_{\text {dep }}=V^{\prime \prime} \times t_{\text {tot }},
\end{gathered}
$$

where: $V^{\prime \prime}$ - volume flux $\left[\mu \mathrm{l} \cdot \mathrm{cm}^{-2} \cdot \mathrm{s}^{-1}\right], V_{\text {dep }}$ - PDI deposition per area $\left[\mu \mathrm{l} \cdot \mathrm{cm}^{-2}\right], t_{\text {tot }}$ - total time $[\mathrm{s}], A_{\mathrm{p}}$ - probe area $\left[\mathrm{cm}^{2}\right], V_{\text {tot }}-$ total liquid volume $[\mu \mathrm{l}], N_{\text {tot }}-$ total number of drops, $\mathrm{D}_{30}$ - volume mean diameter $[\mu \mathrm{m}]$. Quantitative dose data for string treatments was acquired by soaking individual samples for $15 \mathrm{~min}$ with 58 or $166 \mathrm{ml}$ of deionized water, the latter for samples which needed dilution due to fluorimeter saturation. After soaking, a 3-ml-subsample was read and fluorescence recorded in $\mu \mathrm{g} \cdot \mathrm{l}^{-1}$ units using a spectrofluorophotometer (Shimadzu RF-5301PC, Shimadzu Scientific Instruments, Hyoto, Japan) with an excitation and emission wavelength of 403 and $511 \mathrm{~nm}$, respectively. Throughout the fluorometry process, a pyranine standard of $1,000 \mu \mathrm{g} \cdot 1^{-1}$ concentration was tested to ensure calibration was maintained. All samples were matched with their representative tank concentration and the data were normalized accordingly. String data were then normalized against their collection efficiency using Equation 3 and the appropriate string diameter (either 1.7 or $2 \mathrm{~mm}$ ) across all wind speeds and droplet distributions relative to droplet percent volume acquired from the PDI at the time of sampling. These theoretical equations, verified by the work of Fritz and Hoffmann (2008), were used to calculate the theoretical collection efficiencies for the two string types. The derivation of original equations is reported in the works of Hinds (2012), Mercer (2012), and May and Clifford (1967).

The string deposition data were then converted to units of deposition per area $\left(\mu \mathrm{l} \cdot \mathrm{cm}^{-2}\right)$ using Equation 3 and converted to $\mu \mathrm{l}$ by multiplying by 1,000 .

$$
S_{\text {dep }}=\frac{\frac{D_{\mathrm{m}}}{D_{\text {con }}}}{A_{\mathrm{s}}},
$$

where: $S_{\text {dep }}-$ string deposition per area $\left[\mu \mathrm{l} \cdot \mathrm{cm}^{-2}\right]$, $D_{\mathrm{m}}$ - measured dye mass deposited on string per volume sampling solution $\left[\mu \mathrm{l} \cdot \mathrm{cm}^{-3}\right], D_{\text {con }}$ - dye concentration in tank mix sprayer $\left[\mu \mathrm{l} \cdot \mathrm{cm}^{-3}\right], V_{\mathrm{s}}$ - sample solution volume $[\mathrm{ml}], A_{\mathrm{s}}-$ string area $\left[\mathrm{cm}^{2}\right]$. Both $V_{\text {dep }}$ and $S_{\text {dep }}$ can be converted to mass deposition per unit sampler area by multiplying by the density of water $\left(1 \mathrm{~g} \cdot \mathrm{ml}^{-1}\right)$.

\section{Methods for absorption vs. adsorption trial}

Two small studies to assess the physical differences of the two string collectors were performed. The first test was conducted in the wind tunnel where three cotton and three nylon strings were affixed alternatively, $2 \mathrm{~cm}$ apart in the center of the tunnel working section. The tunnel was set at $4.2 \mathrm{~m} \cdot \mathrm{s}^{-1}$ wind speed and stings were exposed to the same water + Pyranine spray for $90 \mathrm{~s}$, a time in which saturation and loss of mass was apparent. Unlike the primary objective, strings for this purpose were left in the wind tunnel until dry ( $\sim 20 \mathrm{~min}$ ). The center $16.3 \mathrm{~cm}$ sections were harvested, bagged and stored as previously mentioned. The second test placed three, $16.3 \mathrm{~cm}$ cotton and nylon string sections directly in a container of the water + Pyranine solution. The strings were left to soak for $5 \mathrm{~min}$. At harvest, strings were individually removed from the solution with forceps and carefully bagged so that any droplets adhering to them remained. Both studies were repeated in time. 


\section{Analysis}

Deposition data were separated by wind speed and exposure time and means separated using Tukey's HSD (honest significance difference) with a 95\% confidence level using $\mathrm{R}$ (version 3.2.0, $\mathrm{R}$ foundation for Statistical Computing, Vienna, Austria).

\section{Results and Discussion}

\section{PDI vs. strings}

To date, there are no data that examine flux or deposition at the heightened wind speeds presented here. Most research has either focused on relative speeds for ground boom or aerial application whereas the current study is examining wind speeds relative to a location near the source of an orchard airblast sprayer (i.e. 1 to $5 \mathrm{~m}$ ). For this, there were few statistical differences between wind speed at the given exposure time, per sampler (Table 1); therefore data were only pooled by wind speed per sampler at each time interval for Figure 2, which is solely for illustration to express the overall trends of the samplers. From this, the initial hypothesis that the PDI will not become saturated and express a linear trend is confirmed. Interestingly, a point of saturation, plateau or decline was not observed with either string type as hypothesized. Instead, exponential accumulation with the nylon was observed beyond
30 s exposure time. Cotton strings performed with linearity although provided heightened deposition beyond $15 \mathrm{~s}$.

As discussed by Jensen and Olesen (2014), a larger portion of spray is lost with orchard sprayers as opposed to ground boom application. Their review on mass balance illustrates the scope of the issue, whereas in vineyards between 10.8 and $25.7 \%$ of the applied spray mass is lost to the air, and fruit tree spray losses were between 20 and $40 \%$. In the current study, both string types "statistically" compared reasonably well with the PDI deposition data up to $8.3 \mathrm{~m} \cdot \mathrm{s}^{-1}$ (Table 1). There was a degree of uncertainty associated with using strings in areas of high spray volume: cotton and nylon samples exhibited standard deviations up to of 25 and 33\% (respectively) while the maximum PDI deviation was only $1 \%$. This would entail that in areas of high concentration/spray volume, (i.e. in close proximity of an orchard airblast sprayer) that measurements using string samplers could be one of the many factors of unaccounted spray in past mass balance studies.

\section{Sampler functionality}

The theoretical string collection efficiencies ranged from 98 to $99 \%$ regardless of string type and wind speed. For cotton string measures, it has been discussed that precise diameters are impractical to discern due to the ambiguous nature of the textile (Fritz

Table 1. Deposition $\left[\mu \mathrm{g} \cdot \mathrm{cm}^{-2}\right]$ among different sampler types

\begin{tabular}{|c|c|c|c|c|c|c|c|c|c|c|c|}
\hline \multirow{2}{*}{$\begin{array}{l}\text { Exposure } \\
\text { time }[\mathrm{s}]\end{array}$} & \multirow[t]{2}{*}{ Sampler } & \multicolumn{10}{|c|}{$\begin{array}{l}\text { Wind tunnel speeds } \\
\qquad\left[\mathrm{m} \cdot \mathrm{s}^{-1}\right]\end{array}$} \\
\hline & & 1.4 & & 4.2 & & 8.3 & & 12.5 & & 16.7 & \\
\hline \multirow{3}{*}{5} & Cotton & $9.35 \mathrm{E}-03$ & $A$ & $1.61 \mathrm{E}-02$ & $A$ & 1.17E-02 & $A$ & $3.24 \mathrm{E}-03$ & $A$ & $2.22 \mathrm{E}-02$ & A \\
\hline & Nylon & $5.53 \mathrm{E}-03$ & $B$ & $1.74 \mathrm{E}-02$ & A & $1.37 \mathrm{E}-02$ & A & $1.93 \mathrm{E}-03$ & B & $1.11 \mathrm{E}-02$ & A \\
\hline & PDI & $\mathrm{n} / \mathrm{a}$ & & $1.24 \mathrm{E}-02$ & $A$ & $1.60 \mathrm{E}-02$ & A & $1.36 \mathrm{E}-02$ & $\mathrm{C}$ & 1.87E-02 & A \\
\hline \multirow{3}{*}{10} & Cotton & $2.83 \mathrm{E}-03$ & A & $5.54 \mathrm{E}-02$ & A & $4.02 \mathrm{E}-02$ & A & $9.65 \mathrm{E}-03$ & A & 4.87E-02 & A \\
\hline & Nylon & 8.98E-04 & $A$ & $3.69 \mathrm{E}-02$ & A & $2.95 \mathrm{E}-02$ & A & $3.48 \mathrm{E}-03$ & B & 5.15E-03 & B \\
\hline & PDI & $\mathrm{n} / \mathrm{a}$ & & 2.19E-02 & A & $2.81 \mathrm{E}-02$ & A & $2.26 \mathrm{E}-02$ & $\mathrm{C}$ & 2.61E-02 & $A B$ \\
\hline \multirow{3}{*}{15} & Cotton & $1.88 \mathrm{E}-02$ & A & $1.12 \mathrm{E}-01$ & A & 8.03E-02 & $A$ & 2.01E-02 & $A$ & 8.89E-02 & A \\
\hline & Nylon & $3.71 \mathrm{E}-03$ & A & $4.81 \mathrm{E}-02$ & A & 4.43E-02 & $A$ & $6.17 \mathrm{E}-03$ & B & $3.50 \mathrm{E}-03$ & B \\
\hline & PDI & $\mathrm{n} / \mathrm{a}$ & & 3.38E-02 & $A$ & 4.10E-02 & $A$ & 3.59E-02 & $\mathrm{C}$ & 5.35E-02 & $A B$ \\
\hline \multirow{3}{*}{30} & Cotton & $1.83 \mathrm{E}-02$ & A & 4.06E-01 & A & $2.60 \mathrm{E}-01$ & A & 5.67E-02 & $A$ & $2.28 \mathrm{E}-01$ & A \\
\hline & Nylon & $2.63 \mathrm{E}-03$ & A & 7.95E-02 & B & 7.91E-02 & A & $1.10 \mathrm{E}-02$ & B & $6.09 \mathrm{E}-03$ & B \\
\hline & PDI & $\mathrm{n} / \mathrm{a}$ & & 7.67E-02 & $A B$ & $9.05 \mathrm{E}-02$ & A & 8.47E-02 & $\mathrm{C}$ & 1.15E-01 & $A B$ \\
\hline \multirow{3}{*}{60} & Cotton & $1.49 \mathrm{E}-01$ & A & 7.65E-01 & A & 7.47E-01 & A & $1.51 \mathrm{E}-01$ & A & 4.54E-01 & A \\
\hline & Nylon & 7.20E-02 & A & $1.27 \mathrm{E}+00$ & A & $3.92 \mathrm{E}-01$ & A & 1.07E-01 & B & $6.68 \mathrm{E}-02$ & A \\
\hline & PDI & $n / a$ & & $1.54 \mathrm{E}-01$ & A & $1.79 \mathrm{E}-01$ & A & $2.02 \mathrm{E}-01$ & C & $2.26 \mathrm{E}-01$ & A \\
\hline
\end{tabular}

Means within column followed by the same letter are not statistically different based upon Tukey's HSD $(p \leq 0.05), n / a-$ no data 


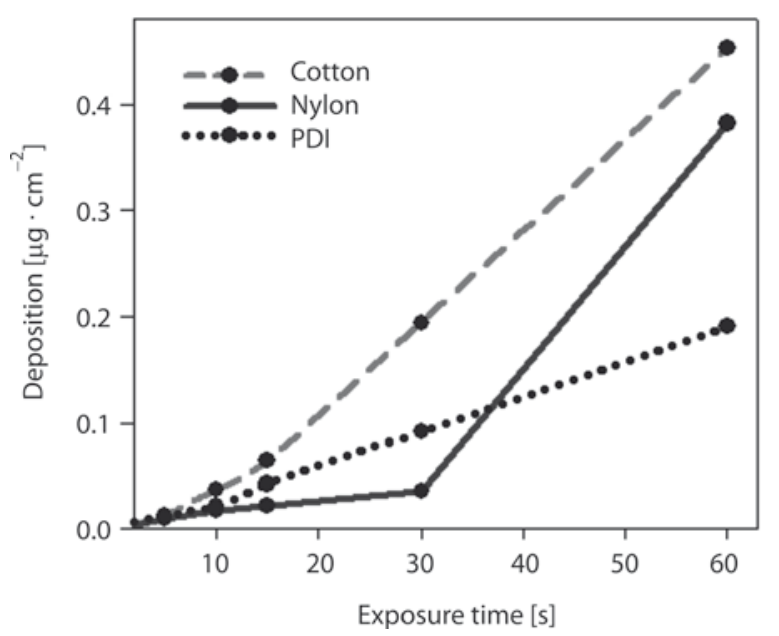

Fig. 2. Deposition data with wind speed pooled per exposure time

and Hoffmann 2008); this is clearly observed in Figure 3A. Diameter is an important parameter when calculating flux. The best estimate of $1.7 \mathrm{~mm}$ was assigned for the cotton string diameter; however, when assessing the collection efficiencies using the same database criteria for diameters of 1.6 and $1.8 \mathrm{~mm}$, efficiencies only differ by $\pm 0.08 \%$. The works of Cooper et al. (1996) explain that fibrous materials, such as yarn, possess the benefit of almost $100 \%$ collection efficiency in circumstances where wind speed is $>1.5 \mathrm{~m} \cdot \mathrm{s}^{-1}$ and droplets are $\geq 15 \mu \mathrm{m}$, which agrees with the current data. It is believed that these fibrous materials are better suited to collecting smaller droplets due to the fine, outstretched strands (Fig. 3B).

Regardless, due to this ambiguity in width, cotton samplers are not believed to provide quantitative spray deposition data as a true sampling area cannot be discerned (Bonds and Leggett 2015). As was observed in the present study with the cotton sampler, consistent tension was difficult to maintain and higher wind velocities had a visible tendency to stretch the sampler; the more these are stretched, the narrower the diameter and less permeable they become resulting in less absorption. This is illustrated in the secondary objective whereas the cotton strings that were left immersed in their neutral position, absorbed $1.970 \mu \mathrm{g} \cdot 1^{-1}$ $\left( \pm 113 \mu \mathrm{g} \cdot 1^{-1}\right)$, whereas when these strings were stretched in the wind tunnel, they only absorbed $566 \mu \mathrm{g} \cdot 1^{-1}\left( \pm 23 \mu \mathrm{g} \cdot \mathrm{l}^{-1}\right)$. The nylon strings, which can only adsorb, retained $238 \mu \mathrm{g} \cdot \mathrm{l}^{-1}\left( \pm 30 \mu \mathrm{g} \cdot \mathrm{l}^{-1}\right)$ when left immersed, whereas $1003 \mu \mathrm{g} \cdot \mathrm{l}^{-1}\left( \pm 174 \mu \mathrm{g} \cdot \mathrm{l}^{-1}\right)$ retained in the tunnel. This increased adsorption can be seen in Figure 4.

The PDI processor validation that provides information regarding the quality of the Doppler signals, ranged between 76 and $90 \%$, which is partially due to the low frequency of droplets passing through the sampling volume (Table 2). Up to $14 \%$ of the droplets counted were dismissed by the PDI software due to a lack of droplet "sinusoidal coherency" (Anonymous 2013). The sampling frequency has been observed to be a common limitation. Previous research has demonstrated that 10,000 to 20,000 counts are necessary for high validations (Dullenkopf et al. 1998; Nuyttens et al. 2007; Tratnig and Brenn 2010). The frequency in the present study for the $1.4 \mathrm{~m} \cdot \mathrm{s}^{-1}$ treatment only provided a range of 9 to 34 counts which indeed caused inaccurate flux data; therefore, these data were not included in the flux/deposition comparisons. However, all other treatments which provided a range of 36 to 901 counts still provide a reasonable flux. Further, previous efforts to compare the Demeter PDI against string measurements illustrated no statistical difference at wind velocities of 1.4 to $4.2 \mathrm{~m} \cdot \mathrm{s}^{-1}$ with sampling frequency of 50 to 4,000 counts (Roten et al. 2015). Therefore, it is apparent that this relationship between sampling frequency and validation rates is dependent upon the hardware and software used.

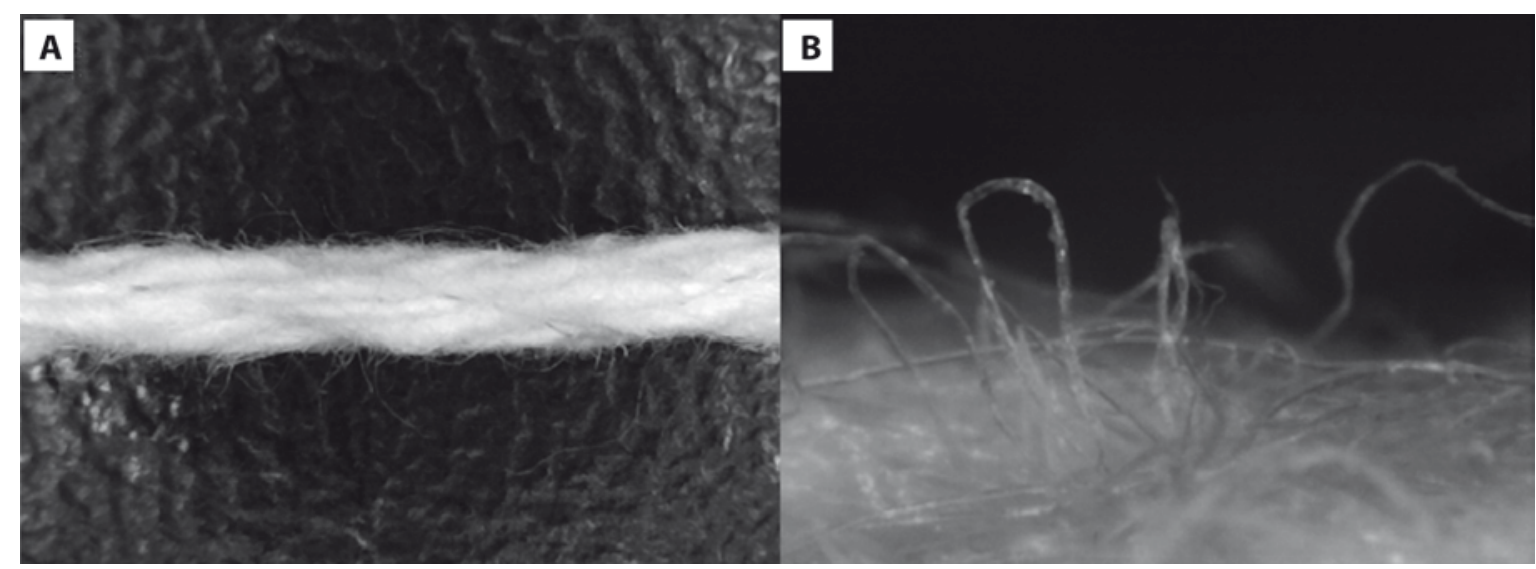

Fig. 3. A - 20x view of the cotton string illustrating physical differences in diameter as well as the fibrous nature of the textile, B - a $400 \times$ view of the outstretched fibers, approximately $15 \mu \mathrm{m}$ thick 


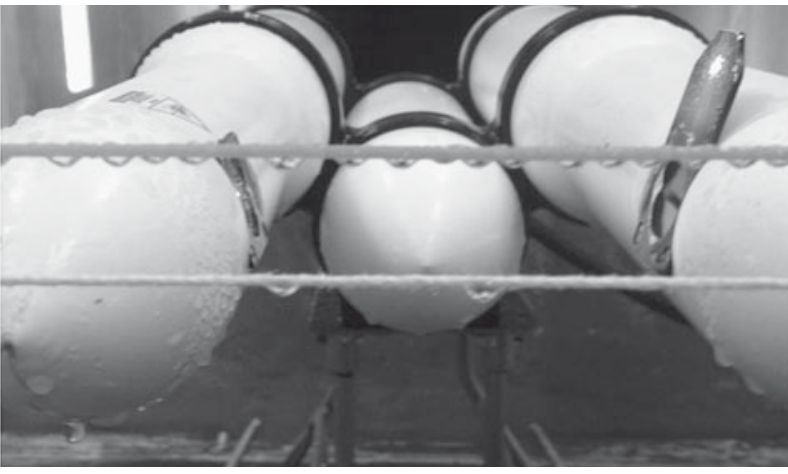

Fig. 4. Illustration of saturation and droplet accumulation on nylon (upper) and cotton (lower) strings

\section{Droplet size and velocity}

Though there is an apparent, linear relationship to the number of samples as the exposure time increases, there is no obvious relation between counts per exposure time by wind speed; in fact, the lowest wind speed observed a higher sampling frequency than all treatments except the $60 \mathrm{~s}$ at $16.7 \mathrm{~m} \cdot \mathrm{s}^{-1}$ treatment (Table 2). This observation could be due to the difference droplet size spectrum being carried by the air. An explanation for this is the shift of droplet spectrum relative to the surrounding air speed (Table 3). Fritz and Hoffmann (2008), using laser diffraction, also observed that as the wind tunnel speed increased, the droplet size data tended to coarsen or increase in average size as larger droplets do not accelerate as rapidly as their smaller counterparts. Also, the larger droplets are expected to fall out of the airblast flow before they reach the probe at lower speeds. At the lower wind speeds, the smaller droplet spectrum consumes a larger part of the cumulative volume that will be carried; therefore, more samples were available to pass the probe volume at the lower speed. Further, the smaller the droplet spectrum, the closer it appears to relate to the surrounding wind speed (Table 3). This could be a valuable tool when assessing the PDI in-field where air velocities can be difficult to accurately obtain, such as with an orchard airblast sprayer.

\section{Conclusions}

The PDI proved to measure flux, velocity, and droplet size in a wind tunnel across wide spray exposure sampling times $(\geq 10 \mathrm{~s})$ and high wind speeds $\left(\geq 16.7 \mathrm{~m} \cdot \mathrm{s}^{-1}\right)$. These measurements confirmed the first hypothesis, that the PDI would exhibit a linear trend as exposure time increased. The secondary hypothesis was only partially correct: smooth nylon and fibrous cotton strings were predicted to saturate and/ or lose mass at a point in time and wind speed as they are static, passive collectors; however, fewer statistical differences were observed than expected. A recurring limitation in this research is the sampling frequencies of the PDI in these spray conditions. However, when cross examined against strings, it is apparent that the severe errors associated with the strings were of greater

Table 2. Sampling frequency (counts/number of droplets) and signal validation rates of the PDI per treatment

\begin{tabular}{|c|c|c|c|c|c|c|c|c|c|c|}
\hline \multirow{3}{*}{$\begin{array}{l}\text { Wind } \\
\text { speed } \\
{\left[\mathrm{m} \cdot \mathrm{s}^{-1}\right]}\end{array}$} & \multicolumn{10}{|c|}{ Exposure time [s] } \\
\hline & \multicolumn{2}{|c|}{5} & \multicolumn{2}{|c|}{10} & \multicolumn{2}{|c|}{15} & \multicolumn{2}{|c|}{30} & \multicolumn{2}{|c|}{60} \\
\hline & $\begin{array}{l}\text { counts } \\
\text { [freq.] }\end{array}$ & $\begin{array}{l}\text { val. } \\
\text { [\%] }\end{array}$ & $\begin{array}{l}\text { counts } \\
\text { [freq.] }\end{array}$ & $\begin{array}{l}\text { val. } \\
{[\%]}\end{array}$ & $\begin{array}{l}\text { counts } \\
\text { [freq.] }\end{array}$ & $\begin{array}{l}\text { val. } \\
{[\%]}\end{array}$ & $\begin{array}{l}\text { counts } \\
\text { [freq.] }\end{array}$ & $\begin{array}{l}\text { val. } \\
\text { [\%] }\end{array}$ & $\begin{array}{l}\text { counts } \\
\text { [freq.] }\end{array}$ & $\begin{array}{l}\text { val. } \\
{[\%]}\end{array}$ \\
\hline 4.2 & 70 & 85 & 125 & 88 & 209 & 85 & 518 & 83 & 890 & 82 \\
\hline 8.3 & 58 & 93 & 94 & 91 & 158 & 90 & 330 & 90 & 750 & 89 \\
\hline 12.5 & 43 & 90 & 100 & 90 & 134 & 87 & 285 & 89 & 606 & 90 \\
\hline 16.7 & 36 & 76 & 84 & 87 & 167 & 88 & 481 & 89 & 901 & 90 \\
\hline
\end{tabular}

Table 3. Measured wind velocity, mean droplet velocity, and size statistics data by wind speed

\begin{tabular}{|c|c|c|c|c|}
\hline \multirow{2}{*}{$\begin{array}{l}\text { Wind speed } \\
\qquad\left[\mathrm{m} \cdot \mathrm{s}^{-1}\right]\end{array}$} & \multirow{2}{*}{$\begin{array}{c}\text { Droplet V } \\
{\left[\mathrm{m} \cdot \mathrm{s}^{-1}\right]}\end{array}$} & \multicolumn{3}{|c|}{ Droplet size [ $\mu \mathrm{m}]$} \\
\hline & & $\mathrm{D}_{\mathrm{v} 0.1}$ & $\mathrm{D}_{\mathrm{v} 0.5}$ & $\mathrm{D}_{\mathrm{v} 0.9}$ \\
\hline 1.4 & 1.4 & $\mathrm{n} / \mathrm{a}$ & $\mathrm{n} / \mathrm{a}$ & $\mathrm{n} / \mathrm{a}$ \\
\hline 4.2 & 4.1 & $125.5 \pm 4.3$ & $139.1 \pm 0.7$ & $198.8 \pm 13.5$ \\
\hline 8.3 & 8.5 & $148.6 \pm 1.3$ & $165.4 \pm 0.6$ & $197.7 \pm 13.1$ \\
\hline 12.5 & 11.3 & $155.3 \pm 4.5$ & $170.8 \pm 0.8$ & $194.7 \pm 4.0$ \\
\hline 16.7 & 15.2 & $165.3 \pm 0.4$ & $187.0 \pm 1.0$ & $209.37 \pm 3.7$ \\
\hline
\end{tabular}


consequence than the errors observed with the PDI. There are several potential sources of error with strings, including the possibility that turbulence causes drops to impinge on the back side of the strings as well as the front, thus increasing sampler deposition. On the other hand, Zhu et al. (1996) showed that increasing the turbulence intensity in a wind tunnel decreased the collection efficiency of samplers. In any case, turbulent air flow in the field can alter the collection efficiency of samplers used. Therefore, the PDI could be a valuable tool in future mass balance assessment, particularly in areas of high spray mass such as with orchard sprayers.

\section{Acknowledgements}

The authors would like to thank the University of Queensland staff that assisted in the experiment including Jason (Connor) Ferguson, Christopher O’Donnell, and Gary Dorr as well as allowing us to use their facility.

\section{References}

Anonymous. 2013. Demeter PDI User Manual: Artium Technologies, Inc.

Bachalo W.D., Rudoff R.C., Brena de La Rosa A. 1988. Mass flux measurements of a high number density spray system using the phase Doppler particle analyzer. 26th Aerospace Sciences Meeting. DOI: https://doi.org/10.2514/6.1988-236

Bonds J.A., Leggett M. 2015. A literature review of downwind drift from airblast sprayers: development of standard methodologies and a drift database. Transactions of the ASABE 58 (6): 1471-1477.

Cooper J.F., Smith D.N., Dobson H.M. 1996. An evaluation of two field samplers for monitoring spray drift. Crop Protection 15 (3): 249-257. DOI: http://dx.doi.org/10.1016/02612194(95)00113-1

Dullenkopf K., Willmann M., Wittig S., Schöne F., Stieglmeier M., Tropea C., Mundo C. 1998. Comparative mass flux measurements in sprays using a patternator and the phasedoppler technique. Particle and Particle Systems Characterization 15 (2): 81-89. DOI: https://doi.org/10.1002/ (sici)1521-4117(199804)15:2<81::aid-ppsc81>3.0.co;2-a

Fritz B.K., Hoffmann W.C. 2008. Development of a system for determining collection efficiency of spray samplers. Applied
Engineering in Agriculture 24 (3): 285-293. DOI: https:// doi.org/10.13031/2013.24497

Fritz B.K., Hoffmann W.C., Birchfield N., Ellenberger J., Khan F., Bagley W., Hewitt A.J. 2011. Evaluation of spray drift using low-speed wind tunnel measurements and dispersion modeling. p. 261-283. In: "Pesticide Formulations and Delivery Systems. 30th vol. Regulations and Innovation". ASTM International. DOI: https://doi.org/10.1520/stp 152720120018

Goguen R.J., Saunders B.A.J., Picot J.J.C. 1997. Flux-based measurements with the malvern spectrometer. Transactions of the ASAE 40 (5): 1233-1236. DOI: https://doi. org/10.13031/2013.21374

Hinds W.C. 2012. Aerosol Technology: Properties, Behavior, and Measurement of Airborne Particles. Wiley, $504 \mathrm{pp}$.

Hoffmann W.C., Fritz B.K., Farooq M., Walker T.W., Czaczyk Z., Hornsby J., Bonds J.A.S. 2013. Evaluation of aerial spray technologies for adult mosquito control applications. Journal of Plant Protection Research 53 (3): 222-229. DOI: https://doi.org/10.2478/jppr-2013-0034

Jensen P.K., Olesen M.H. 2014. Spray mass balance in pesticide application: a review. Crop Protection 61: 23-31. DOI: https://doi.org/10.1016/j.cropro.2014.03.006

May K.R., Clifford R. 1967. The impaction of aerosol particles on cylinders, spheres, ribbons and discs. Annals of Occupational Hygiene 10 (2): 83-95. DOI: https://doi.org/10.1093/ annhyg/10.2.83

Mercer T.T. 2012. Aerosol Technology in Hazard Evaluation. Elsevier, 406 pp.

Nuyttens D., Baetens K., De Schampheleire M., Sonck B. 2007. Effect of nozzle type, size and pressure on spray droplet characteristics. Biosystems Engineering 97 (3): 333-345. DOI: http://dx.doi.org/10.1016/j.biosystemseng.2007.03.001

Roten R.L., Ferguson J.C., Connell R.J., Gary J.D., Hewitt A.J. 2015. Preliminary investigation of phase Doppler derived flux measurements in a wind tunnel for the sampling of orchard spray drift. SuproFruit 2015 - 13th Workshop on Spray Application in Fruit Growing. 15-18 July 2015. Lindau, Germany.

Roten R.L., Post S.L., Werner A., Hewitt A.J., Safa M. 2016. Volumetric validation of mass balance using a computational phase Doppler approach for disc core nozzles. Crop Protection 79: 128-134. DOI: https://doi.org/10.1016/j. cropro.2015.10.018

Tratnig A., Brenn G. 2010. Drop size spectra in sprays from pressure-swirl atomizers. International Journal of Multiphase Flow 36 (5): 349-363. DOI: http://dx.doi.org/10.1016/j. ijmultiphaseflow.2010.01.008

Zhu H., Reichard D.L., Fox R.D., Brazee R.D., Ozkan H.E. 1996 Collection efficiency of spray droplets on vertical targets. Transactions of the ASAE 39 (2): 415-422. DOI: https://doi. org/10.13031/2013.27517 